\title{
Power-Electronics Issues of Modern Electric Railway Systems
}

\author{
Andreas STEIMEL, Senior Member, IEEE \\ Ruhr-University Bochum \\ D-44780 Bochum, Germany \\ steimel@eele.rub.de
}

\begin{abstract}
After de-regulation of the former state-owned railways and severe restructuring of the railway industry in the last 15 years, more innovative vehicle concepts saw the light of the day. Power electronics, already formerly being a pacemaker for progress of traction vehicles, brought forth an utmost standardization of the main drive by means of the IGBT-converter-fed induction motor drive. This is independent of the railway supply voltage system or of a diesel prime mover, for locomotives, high-speed and mass-transit trains as well as for tramways. Vehicles able to operate on all four European railway voltage systems have become feasible and are used now widely. New trends as Permanent-Magnet Synchronous Motors or Medium-Frequency Transformers are discussed, and a short overlook over actual field-oriented highperformance motor control systems - including a speedsensorless variant - is given. Power electronics dominates the field of conversion of the $16.7-\mathrm{Hz}$ railway supply power, typical for Central Europe, from the 50-Hz three-phase utility grid.
\end{abstract}

Index Terms-railway systems, induction motor drive, IGBT-converter-fed

\section{INTRODUCTION}

During the second half of the 20th century, the railways im-portance declined due to the rise of individual transport, in the form of the private motor car and the truck, as well as the air- plane, whose speed and versatility the railway could not apparently match. Only by the close of the century, a change of mind set in: Due to congestion of public traffic by individual transport, track-bound public mass transit becomes more and more appealing. But governmental control proved inadequate to meet the demands to the railway systems; thus, programs of decentralization and deregulation were applied to railway transit. EU Directive 91/440 intended to enable and organize the barrier-free coexistence and competition of governmental and private railway operators, splitting the formerly state-owned railways into industrially-organized, competing train operators and further-on state-owned infrastructure providers.

Ever since the beginning of the 1990s, the European railway industry had to face constant change; the restructuring of the railway organisations by deregulation and privatization led first to a decline in orders and in consequence to amalgamation. Engineering industry divisions formerly responsible for the supply of the mechanical components of traction units were integrated into the transportation divisions of the electrical large-scale industrial companies, the latter now acting as leaders of system technology. This holds most directly for ALSTOM, Siemens and the former ABB/ADtranz; Bombardier Transportation - which absorbed ADtranz and most of the remaining European carbuilders - is part of the Canadian global transportation company Bombardier, while the Swiss "newcomer" Stadler Rail is a carbuilder, who founds on inverters from $\mathrm{ABB}$ Industry. More innovative and - by standardization - at the same time economically competitive vehicle concepts were to be developped.

\section{INNOVATIVE TRACTION MATERIAL}

\section{A. Locomotives}

Since WWII, the four-axle bogie locomotive has been standard in passenger and goods service. The converter-fed induction motor drive allowed "universal" locomotives with high tractive effort at low speed, a rated power of up to 6.4 MW, running stably at maximal speeds up to $357 \mathrm{~km} / \mathrm{h}([1]$; Fig. 1).

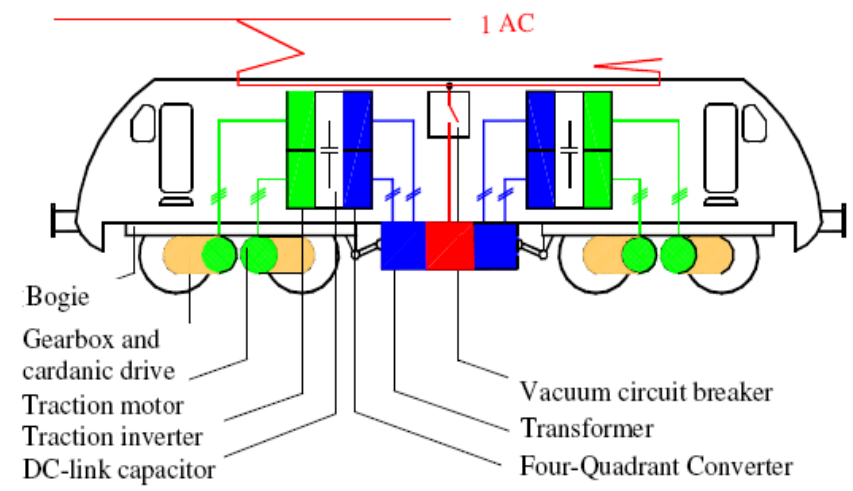

Figure 1. Modern high-power AC-fed bogie locomotive.

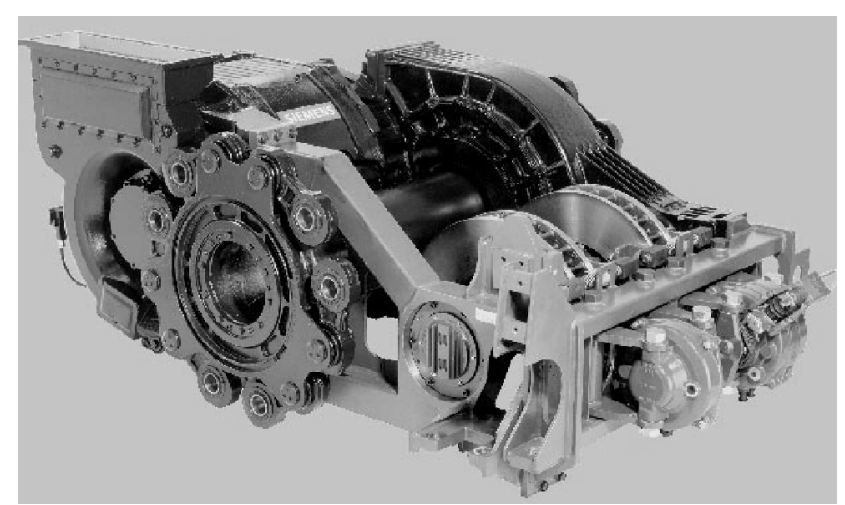

Figure 2. 1.6-MW cardan hollow-shaft drive with rubber joints, brake discs on extra high-geared shaft in front (ÖBB 1216, Siemens).

The bogies are mostly supported by Flexicoil springs; the cardan hollow-shaft drive with rubber joints is standard ([2]; Fig. 2), except for lower-power vehicles, where simpler forms as the "axle-riding" drive with the motor mounted in the bogie and an elastic coupling between motor and gear to the axle or axle-hung motors for low-speed vehicles are sufficient [1]. 
The line-friendly Four-Quadrant Converter (4q-C, [3]) is standard with all AC-fed traction vehicles.

\section{B. High-Speed Trains}

The first generation of high-speed trains (HST) as TGV in France and ICE in Germany pursued the Power Head concept (Fig. 3, top), with special asymmetric, streamlined locomotives and trailers. Due to the heavy axle-load of $18 \ldots 20$ to, this is not suited for speeds over $250 \mathrm{~km} / \mathrm{h}$. The distributed drive with about half or three-quarter of the axles driven with lighter motors prevails now, as in Japanese design, while the electronic equipment and the transformers are mounted underfloor (Velaro [4], AGV [5], $v_{\max }=350$ kph; Fig. 3 bottom). Tilting [6] raises commercial speed up to $220 \mathrm{kph}$ on curved secondary main-lines, where highspeed upgrading is not justified.
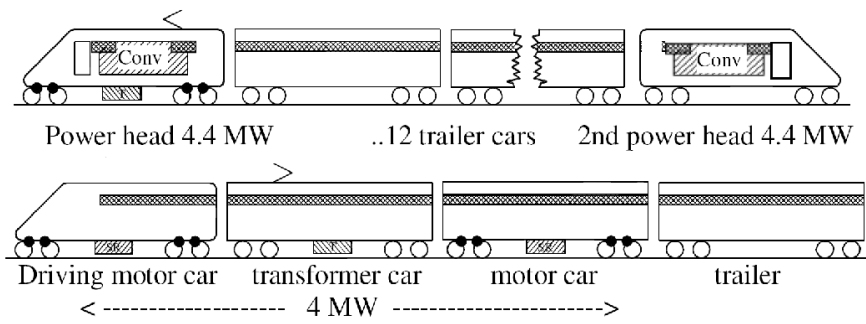

Figure 3. High-speed trains with power heads and as EMUs.

\section{Mass Transit Trains}

The classical EMU Metro Train is supplemented by modern design as bogieless lightweight articulated trains with selfsteering axles or more conventional articulated trains with small-wheel bogies and depressed floors, to ease access from standard 750-mm platforms (Fig. 4); the powerelectronic equipment (and transformer, if $\mathrm{AC}$ ) is mounted underfloor. Modern trains allow to ambulate freely through all coaches, raising the passengers' feeling of safety and thus the acceptance in the late night hours. Self-propelled double-deck commuter EMUs which use the restricted platform lengths of existing suburban and regional railway systems best are ordered increasingly.

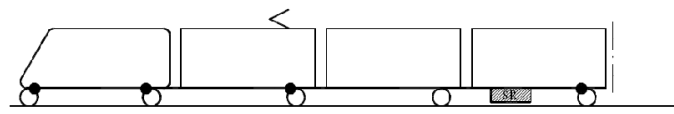

Copenhagen S-Tog articulated EMU $1500 \mathrm{~V}$ DC

Curve-controlled single-wheel sets

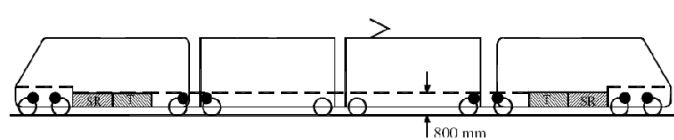

Low-floor articulated EMU DB Cl. 424 $15 \mathrm{kV} 1 \mathrm{AC} 16.7 \mathrm{~Hz}$

Figure 4. Modern Mass-Transit Trains.

\section{Low-Floor Light Rail Vehicles (Tramways)}

To compete better with individual transport, municipal operators and industry strived for raising comfort of tramways by introducing low-floor trains in the nineties of the last century [7]: In the so-called "70\% trams" more or less conventional traction bogies with smaller wheels are used (Fig. 5, top). Single-wheel drives are necessary in the "100\% trams", to allow free passage over the floor, which is only $200 \ldots 300 \mathrm{~mm}$ over ground, accessible directly with one step (Fig. 5 bottom). The power electronic (and airconditioning) equipment has to be mounted on the roofs of the trains.

Dual-system Light Rapid Transit vehicles (Tram Trains) in several German and French cities use the railways' AC lines in an environment of some $150 \mathrm{~km}$ and revert to DC street-level operation when approaching the very centres of these cities.
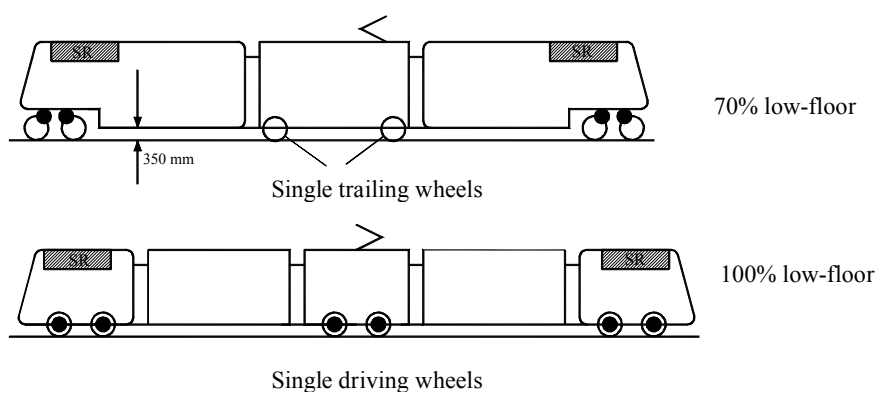

Figure 5. "70\%" and "100\%" low-floor tramways.

This makes public transport more attractive, especially if the main station is far from the city centre. The main constructional difference between light rail and railway vehicles - besides a smaller vehicle gauge and a compromise wheel-tire profile - is the lesser resistance to longitudinal impacts.

\section{RaIlWAy POWER SUPPly Voltage SySTEMS}

Originating from the beginning of the $20^{\text {th }}$ century, four major railway power supply system exist: DC $1.5 \mathrm{kV}$ and 3 $\mathrm{kV}, \mathrm{AC} 50 \mathrm{~Hz}, 25 \mathrm{kV}$ and AC $16.7 \mathrm{~Hz}, 15 \mathrm{kV}$ [8], Fig. 7. The DC $1.5 \mathrm{kV}$ system developed from suburban lines of the big capitals. DC $3 \mathrm{kV}$ was introduced in the twenties, to increase the range.

The AC systems were introduced for long-distance traffic from the beginning. Initially, the special low frequency of $16.7 \mathrm{~Hz}$ was necessary to enable sparkles commutation of the series-wound motor excited with AC. $50 \mathrm{~Hz}$ could only be established after introduction of (first) the mercury-arc and (later) the thyristor-controlled rectifier, together with "undulating-current" DC motors.

The power systems show now rather stable, we only face a superposition of DC systems by $50-\mathrm{Hz}$ systems in case of high-speed, high-power lines, which the old DC systems cannot sustain (France, Spain, Netherlands, Italy).

Table 1 gives an overview of the lengths and the relative proportion of the four main-line power systems. Tramways and underground preferably use DC $600 \ldots 800 \mathrm{~V}$.

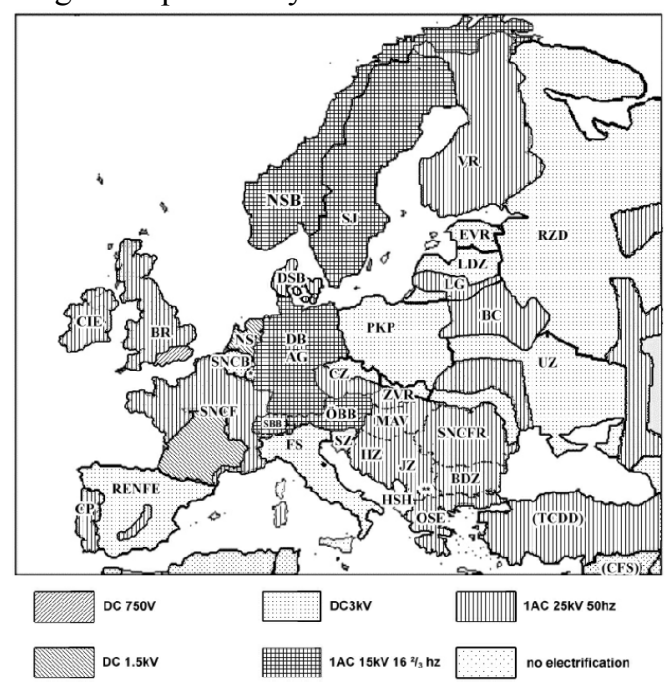

Figure 6. Railway main-line power-supply systems in Europe. 
TABLE I. NETWORK LINE LENGTHS AND PROPORTION OF ELECTRICAL RAILWAY SYSTEMS (2003)

\begin{tabular}{|l|c|c|}
\hline DC $1500 \mathrm{~V}$ & $15,320 \mathrm{~km}$ & $6.5 \%$ \\
\hline DC $3000 \mathrm{~V}$ & $72,105 \mathrm{~km}$ & $30.3 \%$ \\
\hline AC $15 \mathrm{kV} / 162 / 3 \mathrm{~Hz}$ & $32,390 \mathrm{~km}$ & $13.6 \%$ \\
\hline AC $25 \mathrm{kV} / 50$ (and 60$) \mathrm{Hz}$ & $106,437 \mathrm{~km}$ & $44.8 \%$ \\
\hline Others & $11,350 \mathrm{~km}$ & $4.8 \%$ \\
\hline Total & $237,600 \mathrm{~km}$ & $100.0 \%$ \\
\hline
\end{tabular}

\section{MAIN DRIVE CONCEPTS}

In former times, the power system and the main-drive concept were rather rigidly tied together [1]: AC $16.7 \mathrm{~Hz} 15$ $\mathrm{kV}$ appeared mainly with transformer, switch-gear and series-wound, compensated commutator motors; in the seventies, thyristor-control was introduced, mainly in Austria. $50 \mathrm{~Hz}$ necessitated thyristor phase-control, as already mentioned, and DC motors, mainly with separate or mixed excitation. In DC grids, the original camshaft-resistor control of series-wound commutator motors was replaced by thyristor chopper control in the sixties. Multi-system vehicles capable to run on more than two systems were extremely expensive and thus seldom.

The French system of synchronous motors, fed by loadcommutated thyristor converters, as in the TGV-A [9], have shown an intermediate step to the now generally preferred drive system with squirrel-cage induction motors, fed by Voltage-Source Inverters (VSI, [10]). Fig. 6 shows the identical drive structure of DC-fed trams, diesel-electric locomotives and full-electric locomotives with the VSI-IM drive system.

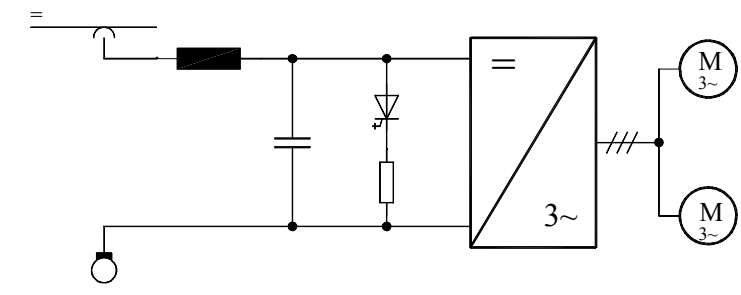

Light-rail vehicle, fed directly from DC $750 \mathrm{~V}$

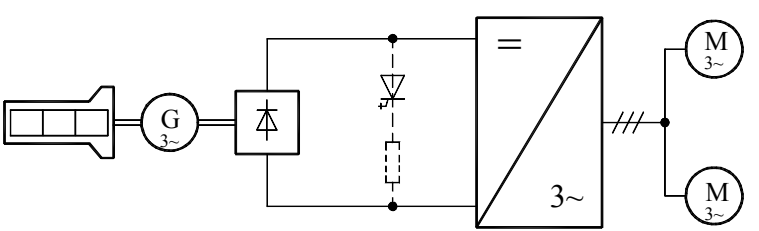

Diesel-electric locomotive with alternator

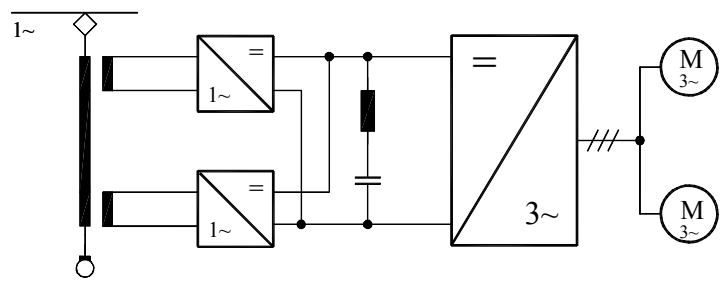

Full-electric locomotive with two Four-Quadrant Converters

Figure 6. Schematic diagram of traction vehicles with three-phase IM drive technology.

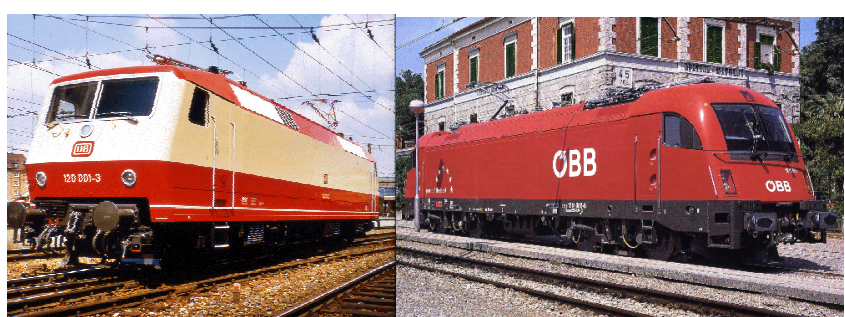

Figure 7. DB Class 120 and Austrian (ÖBB) Class 1216.

The converters were first (from 1971 on) equipped with force-commutated thyristors, as in Class 120 of Deutsche Bahn (DB, Fig. 7, left), later by Gate-Turn-Off (GTO) thyristors [11]. Around the year 2000, the GTO was detached by the IGBT transistor, with blocking voltages of up to $6.5 \mathrm{kV}$ and turn-off currents of $600 \mathrm{~A}$ [12], which can be turned off safely even in short-circuit condition. As they are able to operate directly from the $3 \mathrm{kV}$ overhead lines (with transients up to $5 \mathrm{kV}$ ), they allow a very simple and robust multi-system concept, as in ÖBB (Austria) Cl. 1216 "Taurus", Fig. 6, right; Siemens ([2]).

An alternative concept uses the line-side Four-Quadrant Converter as step-up chopper in the $1.5 \mathrm{kV}$ DC grid and as step-down chopper in the $3-\mathrm{kV}$ grid (Swiss $\mathrm{Cl}$. 484, circuit Fig. 8, [14]). This allows use of 4.5-kV IGBT with better switching characteristics and less voltage stress of the motor insulation, as the DC-link is always kept constant at $2.8 \mathrm{kV}$ (Bombardier).
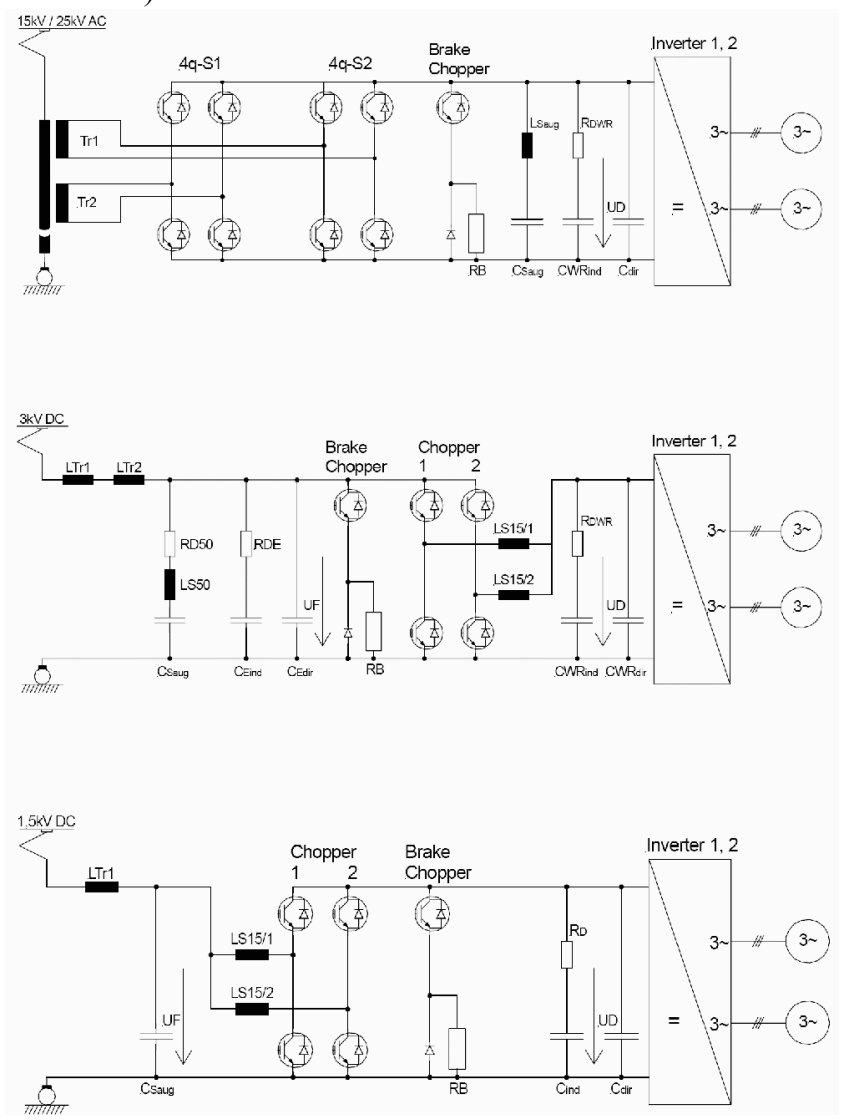

Figure 8. Circuit diagram of SBB Class 484 four-system locomotive.

Diesel-electric locomotive (which by far stand for the biggest part of locomotives all over the world) with $\mathrm{AC}$ generator and diode bridge rectifier can now be built to the same "platform" design as full-electric locomotives, with same starting effort, but about half the rated power, due to the weight of the engine. Bombardier unified the 
construction thus that in the same carbody with identical bogies and motors the electric "E-PowerPackage" can be replaced by a "D-PowerPackage" [14].

Fig. 9 shows a recent air-cooled 200-kW IGBT inverter for $600 \ldots 750 \mathrm{~V}$ from the German manufacturer VosslohKiepe, for tramways and trolley busses, Fig. 10 a converter TC 3200 from Bombardier, for one bogie of a high-power locomotive or a HST power-head.

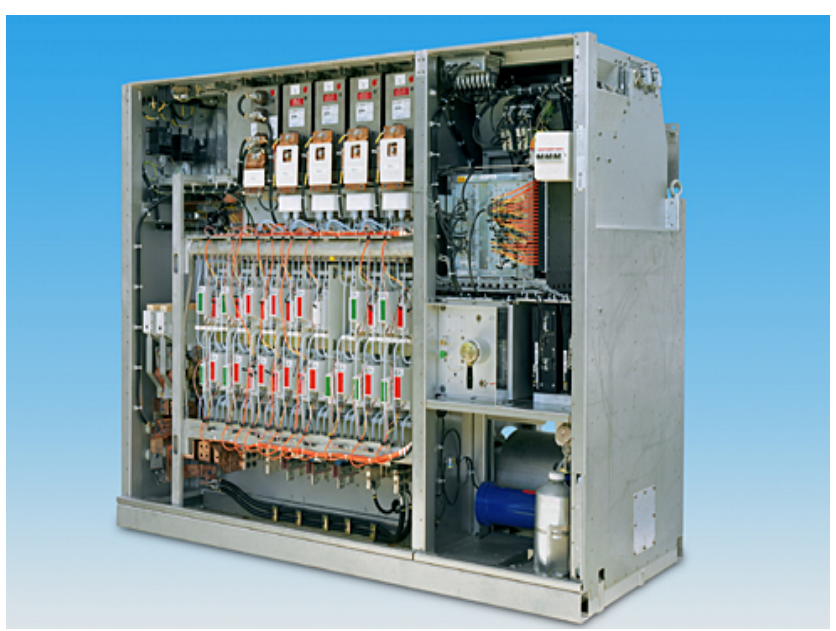

Figure 9. Inverter Vossloh Kiepe DPU 409 for light-rail application.

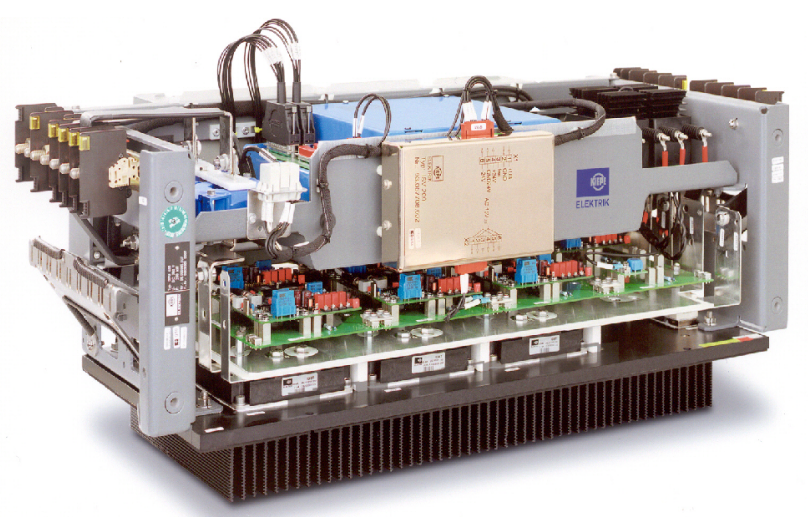

Figure 10. Inverter Bombardier TC 3200 for high-power locomotives.

\section{NeW TREnds In DRIVE CONCEPTS}

\section{A. On-Board Energy Storage}

Energy storages are of interest for intermediate storage of the brake energy, for reduction of the peak power demand and infrastructure losses, to enable short sections without catenary in historic cities, in shops or at track works and for relieving a diesel motor at acceleration, rated for the average power only.

Flywheel storages have been tested in hybrid busses and trams, e.g. in Rotterdam. They are built of very strong carbon-fibre materials and driven by inverter-fed permanent-magnet synchronous machines (PMSM); the maximum attained speed is at $12,000 \mathrm{rpm}$, the usable energy $1.5 \ldots 2 \mathrm{kWh}$.

Supercap storages, coupled with two-quadrant converters to the DC link, have been tested for several years at the municipal tramways of Mannheim [15]; now an order of 18 trains for Heidelberg is under delivery (Bombardier MITRAC Energy Saver).
Nice City Light Rail is bridging wireless sections, not equipped with overhead contact line, of less than $450 \mathrm{~m}$ by means of a NiMH high-performance battery, since July 2007.

\section{B. Permanent-Magnet Synchronous Motors}

Recently new technologies for synchronous motors, like the permanently-excited type with rare-earth magnets (PMSM, [16]), fed from individual IGBT inverters, are under test. As they offer a considerably higher power-toweight ratio than induction motors, they are most promising for HSTs and low-floor suburban and tram equipment, where "each cubic centimetre counts".

There are two main development lines:

\section{1) Conventional drive construction}

That means standard drive construction with gears and elastic coupling, as used e.g. in the new AGV drive [5]. The drive has proven its performance when boosting the TGV V150's maximum speed to $574.8 \mathrm{kph}$ on $3^{\text {rd }}$ of April, 2007. A first series of 25 trains is under delivery for the Italian railway enterprise NTV. ALSTOM markets PMSM in new CITADIS low-floor tramway cars.

2) Gearless drive

Due to the high power-to-weight ratio, PMSM can do away with the heavy gear-box and enable an oil-free drive chain [17]. In the SYNTEGRA drive (150-kW range for underground and trams, Fig. 5.8, [18]) the rotor is fixed to the shaft of the wheel-set. Due to the direct linking of the motors to the carbody, the load transfer is reduced much.

Efficiency of PMSM is claimed to be some $3 \%$ higher than with IM drives, but special precautions must be taken to limit overvoltage when the inverter trips at high speed or to separate a faulty inverter from the motor, as the excitation cannot be terminated. Field weakening for minimising the stator current in the voltage-control region and for constantvoltage operation is performed by impression of demagnetising current components by the inverter; fieldoriented control (cf. section VI) can be performed without rotor-position sensors now.

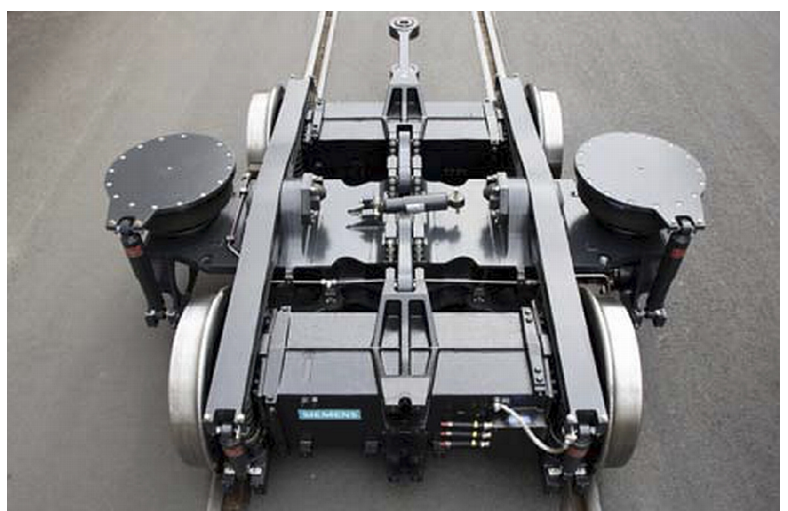

Figure 11. SYNTEGRA bogie with two gearless PMSM.

\section{Medium-Frequency Transformer}

To avoid the enormous weight of the $16.7-\mathrm{Hz}$ transformer, a new topology was developed using a medium-frequency (e.g. $5 \mathrm{kHz}$ in the $\mathrm{MW}$-power range). The $15-\mathrm{kV}$ line voltage is rectified by 8 cascaded modules with $6.5-\mathrm{kV}$ IGBTs connected in series, each comprising of an input H-bridge and a (resonantly operated) output halfbridge, feeding the MF transformer primary (Fig. 12). 


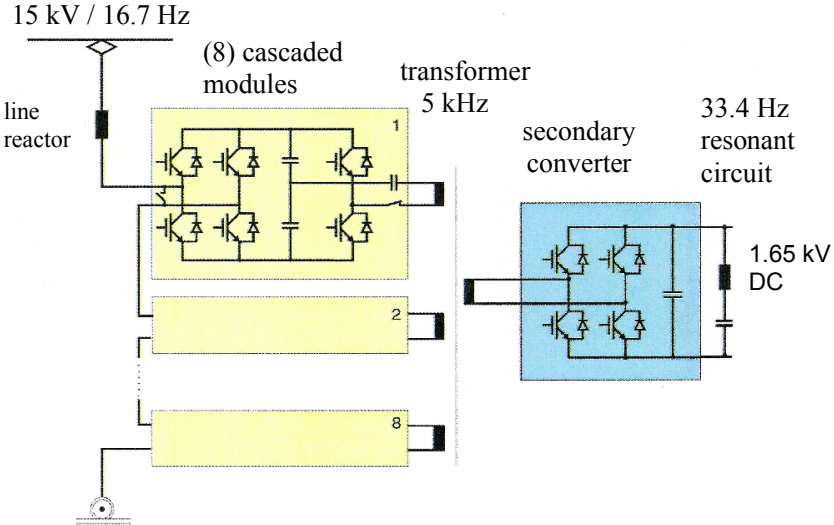

Figure 12. Basic topology of a energy supply system with mediumfrequency "electronic" transformer.

As the secondary converter is equipped with IGBTs, too, the converter is for both power-flow directions. A 1.5-MW prototype was built by ALSTOM and SMA in 2002 (total weight 3 to, efficiency including converters 94\%) [19]. Unfortunately, the prototype was not integrated into a prototype hybrid multiple unit as intended.

Drive Control Issues

With increasing power at the wheel rim and with higher exploitation of the instantaneously changing wheel-rail contact adhesion, the original simple, quasi-stationary "SlipFrequency-Current-Characteristic Control" [20], [1] did not suffice anymore, especially to damp drive oscillations excited by slip-stick effects at slip and slide events [1].

\section{Rotor-field-oriented or Vector Control}

In industrial drives so-called "field-oriented" control schemes had already been introduced in the early eighties. Now they were transferred to traction drives, too. The high computational power of Microprocessors $(\mu \mathrm{P})$ and Digital Signal Processors (DSP) allowed much higher complexity than discrete circuitry before.

Rotor-flux-oriented control [20], [21] calculates amplitude and phase of the rotor-field vector from measured values of inverter output voltages, stator currents (and speed or rotor position) in a machine model. The measured stator currents are decomposed into two orthogonal components in reference to the rotor-field vector, "flux-determining" parallel component and the quadrature "torque-determining" component.

These components - being constant in steady-state - are compared with their reference values in standard linear PI controllers. Finally the controller outputs - the statorvoltage set values in rotor-flux coordinates - have to be transformed back to the stator-winding-fixed reference frame, in which the subsequent Pulse-Width Modulator works.

One problem is the open integration of rotor flux in the Machine Model, which forces to limit the lowest operation frequency and thus to change to the rotor-position-based socalled "Indirect Field Orientation", needing an incremental speed sensor [20], [22]. The other problem is that field orientation works optimally with sinusoidal currents, but gets worse with the strongly distorted current of high-power converters with low switching frequency.

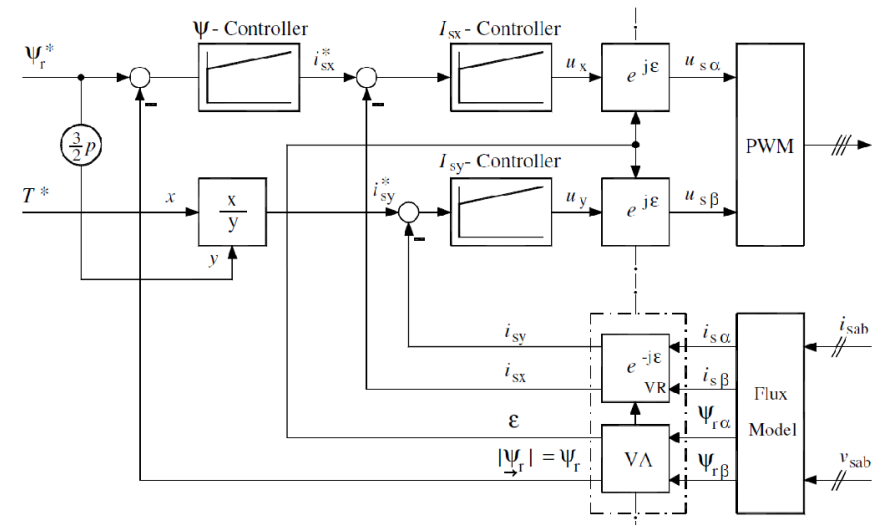

Figure 13. Principle of Direct Rotor-Field Orientation.

\section{E. Stator-flux-oriented control}

Stator-flux orientation leads the tip of the stator-flux space phasor by control on a predetermined trajectory, in the case of low switching frequency (GTO converters) on a regular hexa-gon or an eighteen-corner curve (Flux SelfControl); the radius of this trajectory equals the modulus of the stator-flux space vector. The actual values are estimated in a Machine Model from measured stator currents and stator voltages, modelled from measured DC-link voltage and IGBT switching commands. The tracking speed is given by the torque controller, in case of the original Direct Self Control [23], [24], [20] by direct hysteresis control with overlaid average switching-frequency control, allowing optimal torque dynamics. This control is increasingly detached by quasi-synchronous pulsing [25], [26], with the switching points derived from reaching preset stator-flux thresholds. This is mainly due to the less critical line interference of a synchronous pulsing.

In case of high switching frequency (IGBT converters) a multi-corner polygon, nearly a circle, is chosen without detriment, meaning mainly sinusoidal currents; the stator voltages are controlled by PWM. Indirect Stator-Quantities Control (ISC, [27], [28], [20], [1]) again controls the statorflux modulus - as the radius of the trajectory - by means of a flux modulus controller (output $k_{\Psi}$, Fig. 14). The tracking speed - in the sampled system the angular increment $\Delta \chi_{\mu}$ per sampling period $T_{\mathrm{m}}$ - results from the output of a linear torque controller, backed by a feed-forward $\Delta \chi_{\mu \text { Stat. }}$ The inputs of this controller are first converted to slip-frequency values, to prevent breakdown of the machine easily by limiting the set value to some $80 \%$ of rotor breakdown frequency $\omega_{\mathrm{rK}}$.

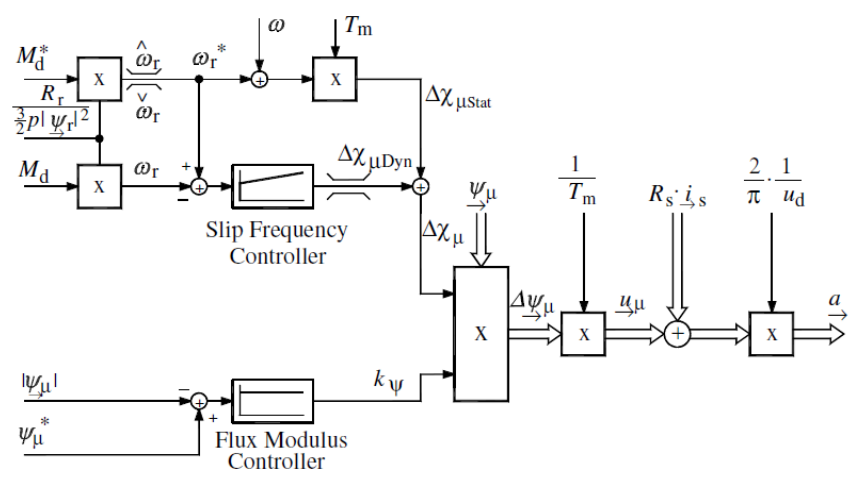

Figure 14. Principle of Indirect Stator-Quantities Control (ISC). 
The two controller outputs $k_{\Psi}$ and $\Delta \chi_{\mu}$ are processed in block $\mathrm{X}$ into the necessary change of the stator-flux space vector in the next sampling period, $\Delta \underline{\Psi}_{\mu}$, which divided by the sampling period delivers the inner (magnetizing) voltage $\underline{u}_{\mu}$. To that the voltage drop at the stator resistance $R_{\mathrm{s}} \underline{i}_{\mathrm{s}}$ is added; the result, normalized to $U_{\mathrm{d}}$, is the input for the Pulse-Width Modulator

In addition, but not shown here, a very effective Dynamic Field-Weakening is provided in this controller [27]. The Machine Model delivers the model stator currents, which are compared in a Luenberger Observer with the measured values, to compensate parameter and inverter voltage errors [28]. This control is highly dynamic, especially in the fieldweakening region, and very robust against input voltage disturbances.

This control has been taken as basis for a speed-sensorless control, doing away with sensitive and damage-prone sensors in the bogie-mounted motors. To that purpose, the mentioned errors are compensated diligently in a feedforward manner; thus the Luenberger Observer is not needed anymore, and the comparison of measured $\left(\underline{i}_{\mathrm{sw}}\right)$ and modelled $\left(\underline{i}_{\mathrm{s}}\right)$ stator-current space vectors is used to estimate two other parameters, that is speed and stator resistance [28]. A stator-current DC-component observer suppresses of "unwanted" (parasitic) DC components in stator flux and current, allowing operation with very low frequencies $(\approx 1 \%$ $\left.f_{\text {rated }}\right)$. A special flux-amplitude management enables speed estimation even at stator frequency zero and thus stopping a train running slowly down and accelerate in the opposite direction, without any speed sensor signal.

[29], [30] report on the successful implementation of a speed-sensorless system, based on the described one, in the new SITRAC Siemens traction control, which has been intensively tested in different light-rail and Metro applications all over the world and is now the standard solution for Siemens Underground and Metro trains.

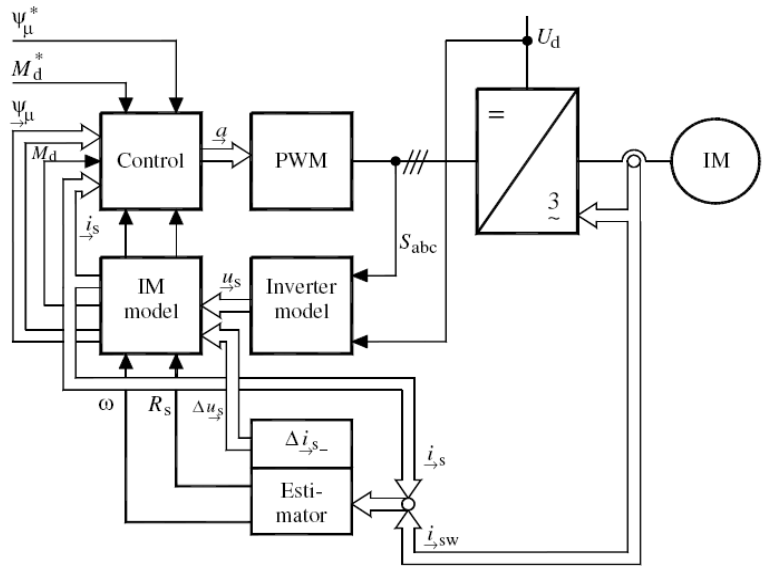

Figure 15. Overall block structure of speed-sensorless ISC.

\section{RAILWAY POWER-SUPPLY SYSTEMS ISSUES}

An overview over the existing four main-line electric power supply systems has been given in section III. This section discusses the influence of power electronics in this field.

\section{A. DC supply system.}

DC supply systems are generally fed by diode rectifiers in 6- or 12-pulse connection. In mass transport systems, own three-phase medium-voltage (MV) busbars are employed for equalizing peak loads, before connecting to the public mains. Thyristor-equipped rectifiers, feeding back brake power, are in use only with mountain railways. Instead, there is an increasing use of energy storages as rotary storages or Supercaps in substations, to recover brake energy and/or support the supply voltage.

\section{B. AC 50-Hz supply systems}

Very few power-electronic components are in use in 50$\mathrm{Hz}$ systems. Commonly, separate feeding sections are connected to subsequent phases of the three-phase MV grid, to reduce the imbalance of load. The protective insulations have to be crossed with opened main switch. Inverters for reactive power compensation are used only in special situations (Channel Tunnel, Tokyo-Osaka).

\section{AC 16.7- $\mathrm{Hz}$ supply systems}

Totally different is the situation in the Central European $16.7-\mathrm{Hz}$ grids, which are owned by the infrastructure operators. The catenary is coupled through longitudinally and from track to track, yielding a very high quality of service and enabling a high degree of regeneration of brake power, made possible by the generally employed $4 \mathrm{q}-\mathrm{C}$ line converters.

Static converters are used more and more, to replace old single-phase power stations and rotary converters, feeding into the interconnected $110-\mathrm{kV}$ transport grid $(132 \mathrm{kV}$ in Switzerland). The incentive is similar as with the drives, but here the point is that no supplier is willing to construct new single-phase $16.7-\mathrm{Hz}$ generators anymore, as the market is too small.

The standard solution are single-phase bridge inverters with IGCT (ABB inverter [31]) or press-pack IGBT (Converteam inverters [32]) in three-level NPC technology. Today, the same inverter modules are used in the threephase 50-Hz side converter, too (Fig. 16).

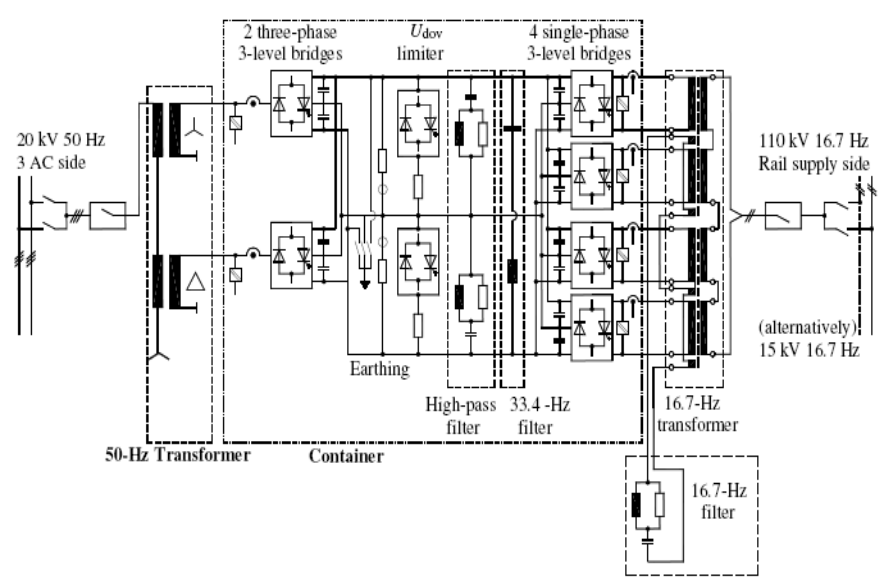

Figure 16. Main circuit diagram of 15-MW standard railway supply converter, using IGCT elements (ABB Switzerland AG).

The output voltages of the $16.7-\mathrm{Hz}$ single-phase inverters are switched synchronously in 3-fold mode, with staggered angles for each inverter; all four are added by two doublestage transformers, with integrated filter tertiary winding. Fig. 17 shows the output voltages of the two bridge branches $\mathrm{A}$ and $\mathrm{B}$, and the resultant bridge voltage $\mathrm{u} 2=\mathrm{uA}-\mathrm{uB}$, with five levels and six angles per $90^{\circ}$, together with the load current i2. 


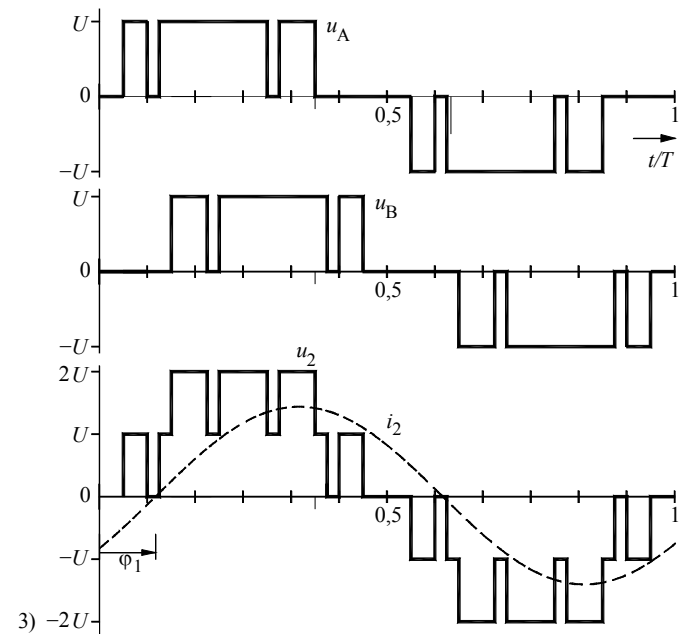

Figure 17. Voltage waveforms of three-level single-phase inverter.

In Datteln, West Germany, at the site of the new E-On 1100-MW hard-coal fired power plant world's largest railway-power supply converter station will be built by ABB. After completion and commissioning in 2011 it will convert up to $413 \mathrm{MW} 50-\mathrm{Hz}$ three-phase power into 16.7 $\mathrm{Hz}$. The converter station consists of four converter blocks, which ensure $n-1$ redundancy due to their overload capability, to absorb a failure of one block and to provide maintenance under full-load [33].

An alternative design is the Modular Multilevel Converter $\left(\mathrm{M}^{2} \mathrm{LC}\right)$. Fig. 18 shows a schematic diagram of a railwayintertie converter [34]. Two chains of each $n$ two-quadrant chopper modules (shown at bottom-right) are connected in series per pole, the storage capacitors $C$ of which are not fed from exterior voltage supplies, but float more or less freely and have to be equalized by control. There is no common high-voltage dc-link capacitor, the transformers are more or less standard.

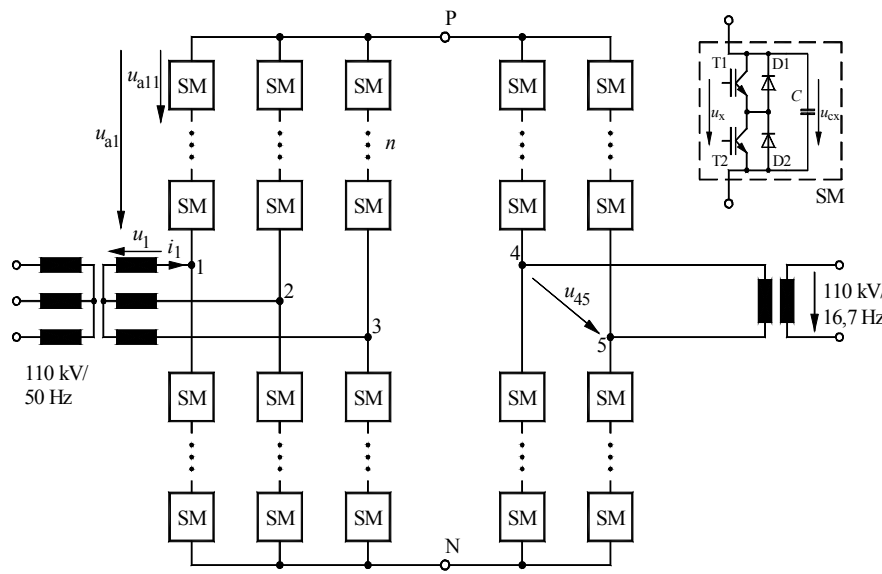

Figure 18. Modular Multilevel Converter three-phase to single-phase.

The output voltage waveform is $(2 n+1)$-stepped. As the power conversion is performed in single-phase mode, separately for each pole, the capacitors have to take up the single-phase power pulsation, which leads to a considerable voltage ripple, mainly with $16.7 \mathrm{~Hz}$, but resonant circuits are not necessary.

Fig. 19 shows for an example of $n=8$ the quantities of the three-phase side. The storage-capacitor voltage variation can be seen clearly in the tops of the module input voltage.

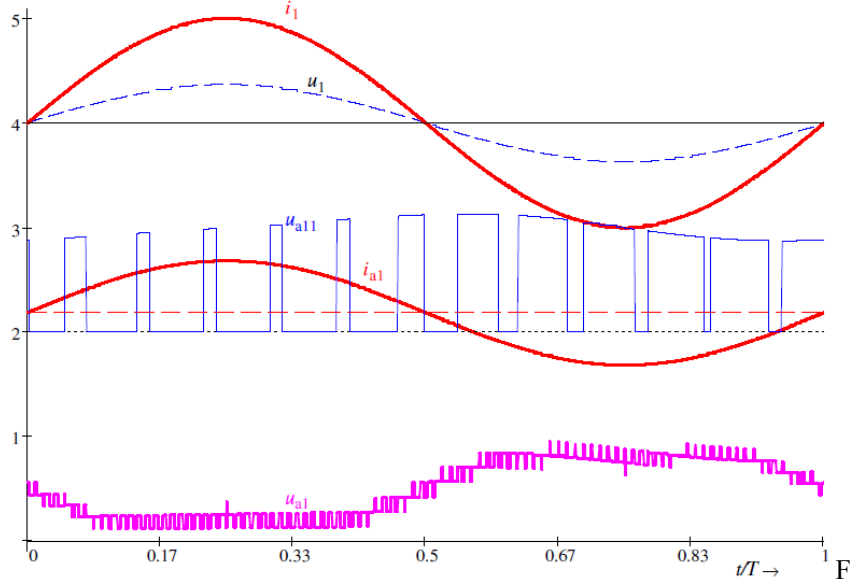

Figure 19. Line voltage $u_{1}$ and line current $i_{1}$, module voltage $u_{\mathrm{a} 11}$ and arm current $i_{\mathrm{a} 1}$, arm voltage $u_{\mathrm{a} 1}$ of a $\mathrm{M}^{2} \mathrm{LC} . n=8, f_{\text {zmodule }}=600 \mathrm{~Hz} \cdot u_{1}$ and $u_{\mathrm{a}}$ normalized to $U_{\mathrm{PN}, \text { rated }} ; u_{\mathrm{a} 11}$ to $U_{\mathrm{PN}} / n$, currents to $\hat{l}_{1, \text { rated }}$.

Five plants for the Swedish and two for the German infrastructure company are under contract with Siemens.

D. Instability effects in railway grids with power-electronic traction vehicles

Besides the well-known resonances of the railway line voltage, excited by the harmonics of the switching frequency [1], but now enforced by the increased cabling of line feeders in the Alps tunnels and agglomeration areas, new phenomena of instability appear with the massive propagation of power- electronic traction vehicles.

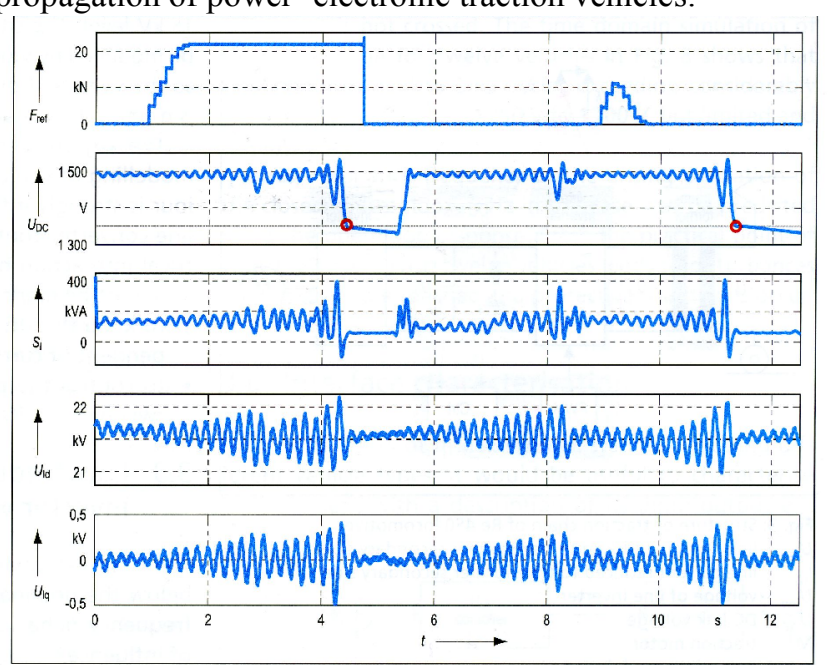

Fig. 1: Low frequency power oscillation measured on Re 450 locomotive at Bonstetten-Wettswil station on 23rd of September 2004.

$F_{\text {ref }}$ reference value for traction effort of bogie 1

$U_{D C}$ DC link voltage

$S_{1} \quad$ line power

$U_{\text {ld }} \quad$ line voltage amplitude (d-component)

$U_{\text {lq }}$ line voltage phase (q-component)

Line values related to vehicle transformer primary side

Figure 20. Low-frequency (5 Hz) power oscillations in Switzerland.

In 2004, in Zurich severe grid-power oscillations with very low frequency were observed, where many converter locomotives and only few classic notch-controlled vehicles were in service. In trials these oscillation - which let to the repeated shutdown of the locomotives - were traced back to limit-cycle oscillation between line inductance and dc-link filter capacitor.

Fig. 21 (from [35]) shows a swelling oscillation of line voltage (graph 4) and dc-link voltage (graph 2), which - by dc-link under-voltage at $t=4.3 \mathrm{~s}$ and $9.2 \mathrm{~s}-$ led to the shutoff of the tractive effort (graph 1). A longer line length 
or a greater number of vehicles can be exchanged against each others.

In further investigations [36] the decisive influence of the integral gain of the dc-link voltage controller was identified; an advanced multivariable control allows to increase the proportional gain, so that any integral gain can be dispensed with.

\section{CONCLUSION}

The intense competition after deregulation of railways and the new formation of railway industry led to many innovative designs of electric traction vehicles, attractive for the customer and economic to operate, mainly enabled by high-performance induction machines fed by IGBT converters and the high degree of modularity it offers for a broad variety of traction vehicles. Field-oriented control, mainly that in the stator-flux-oriented variant, allows to exploit the increased tractive power stably, at uncertain wheel-rail contact and with vibratory drive chains. Powerelectronic converters dominate now the power supply in the Central European 16.7-Hz interconnected grid.

\section{ABBREVIATIONS}

$\begin{array}{ll}\text { AGV } & \text { Automotrice a Grande Vitesse (High-Speed Railcar) } \\ \text { EMU } & \text { Electric Multiple Unit } \\ \text { HST } & \text { High-Speed Train } \\ \text { ICE } & \text { Inter-City Express } \\ \text { IGBT } & \text { Insulated Gate Bipolar Transistor } \\ \text { IGCT } & \text { Integrated Gate-Commutated Thyristor } \\ \text { IM } & \text { Induction Motor } \\ \text { NPC } & \text { Neutral-Point Clamped } \\ \text { PMSM } & \text { Permanent-Magnet Synchronous Machine } \\ \text { SMA } & \text { SMA Technologie AG, D-34266 Kassel } \\ \text { TGV } & \text { Train a Grande Vitesse (High-Speed Train-set) } \\ \text { VSI } & \text { Voltage-Source Inverter }\end{array}$

\section{REFERENCES}

[1] Steimel, A.: Electric Traction: Motion Power and Energy Supply Oldenbourg-Verlag München, 2008

[2] Schurig, J.: Die Mehrsystem-Lokomotive ES 64 U4 (OBB-Reihe 1216). Eisenbahn-Revue 5/2005, pp. 2220228, 6/2005, pp. 268274 and $7 / 2005$, pp. 333335 .

[3] Kehrmann, H.; Lienau, W.; Nill, R.: Vierquadrantensteller - eine netzfreundliche Einspeisung für Triebfahrzeuge mit Drehstromantrieb.

Elektrische Bahnen 45 (1974), Nr. 6, pp. 135-142

[4] Möller, D.; Schlegel, C.: Velaro - Further Development of the ICE for Worldwide Use. Elektrische Bahnen 104 (2006), Nr. 5, pp. 258263.

[5] ***, Alstom präsentiert den Hochgeschwindigkeits-Triebwagenzug AGV.

Eisenbahn-Revue 3/2008, S. 117124

[6] Kurz, H.; Weschta, A. (editors): ICE T, BR 411, 415 und 605. HestraVerlag Darmstadt, 2000

[7] ***, Funf Jahre OPNV-Niederflur-Schienenfahrzeuge. Stadtverkehr Fachzeitschrift fur den offentlichen Personen-Nahverkehr, spezial 1993. EK-Verlag Freiburg, 1993.

[8] H. Gladigau, A.: Historische Entwicklung und Stand der Bahnstromsysteme. Elektrische Bahnen 85 (1987), Nr. 12, pp. 383-390

[9] Coget, G.: The new generation of SNCF high-speed rolling stock: The TGV-Atlantique train. Rail Engineering Intern. 1986, Nr 3, pp. 15-18

[10] 120 - Elektrische Lokomotive in Drehstromtechnik der Deutschen Bundesbahn. Special print of journal "Elektrische Bahnen". R. Oldenbourg Verlag GmbH, Munich, 1984.

[11] Lienau, W.; Runge, W.: Development Trends of High Power Traction Converters. 4th Europ. Conf. on Power Electronics, Florence 1991
[12] Bakran, M. M.; Eckel, H.-G.: Traction Converter with 6.5kV IGBT modules. 9th Europ. Conf. on Power Electronics, Graz 2001.

[13] Gerster, C.; Skarpetowski, G.; Sommer, H.; Still, L.: Advanced multisystem traction chain for locomotives and power heads. 10th Conf. on Power Electronic and Motion Control (EPE-PEMC), Riga 2004

[14] Buscher, M.; Kock, F.; Trotsch, P.; Bikle, U.: TRAXX: Integrale Plattform zur Steigerung der Wettbewerbsfahigkeit des Schienenverkehrs. ETR - Eisenbahntechnische Rundschau 9/2006

[15] Steiner, M., Scholten, J.: Energy Storage onboard of railway vehicles, 11th Europ. Conf. on Power Electronics, Dresden 2005

[16] Binder, A.; Greubel, K.; Piepenbreier, B.; Tolle, H.-J.: PermanentMagnet Synchronous Drive with Wide Field-Weakening Range. ETEP Vol. 8 (1998), No. 3, S. 157-166

[17] Jöckel, A.: Getriebelose Drehstromantriebe für Schienenfahrzeuge Elektrische Bahnen 101 (2003), H. 3, S. 113-119

[18] Jockel, A.; Lowenstein, L.; Teichmann, M.; Hoffmann, Th.; v. Wangelin, F.: Syntegra - Innovativer Prototyp einer nachsten Triebfahrwerk-Generation. Elektrische Bahnen 104 (2006), Nr. 8/9, pp. 360-369

[19] Engel, B.; Victor, M.; Bachmann, G.; Falk, A.: 15 kV/16.7 Hz Energy Supply System with Medium Frequency Transformer and $6.5 \mathrm{kV}$ IGBTs in Resonant Operation. 10th Europ. Conf. on Power Electronics (EPE), Toulouse 2003

[20] Steimel, A.: Control of the induction machine in traction. Elektrische Bahnen 96 (1998), Nr. 12, pp. 361-369

[21] Blaschke, F.: The principle of field orientation as applied to the new TRANSVECTOR closed-loop control system for rotating machines. Siemens Review (1972), S. 217-226

[22] Gedeon, G.; Klausecker, K.; Lang, W.: Mikrocomputer-Ansteuerung fur ICE. Elektrische Bahnen 86 (1988), Nr. 7, pp. 229-235

[23] Depenbrock, M.: Direct Self-Control (DSC) of Inverter-Fed Induction Machine. IEEE Trans. on Power Electronics, vol. 4, pp. 420-429, 1988

[24] Jänecke, M.; Kremer, R.; Steuerwald, G.: Direct Self Control (DSC), A Novel Method Of Controlling Asynchronous Machines in Traction Applications. Elektrische Bahnen 88 (1990), No. 3, pp. 81-87

[25] Worner, K.; Steimel, A.; Hoffmann, F.: Highly Dynamic Stator Flux Track Length Control for High Power IGBT Inverter Traction Drives. 8th Europ. Conf. on Power Electronics and Applications (EPE), Lausanne 1999.

[26] Steimel, A.: Direct Self Control and Synchronous Pulse Techniques for High-Power Traction Inverters in Comparison. IEEE Transactions on Industrial Electronics, Vol. 51 (2004), No. 4, pp. 810-820

[27] Janecke, M.; Hoffmann, F.: Fast Torque Control of an IGBT-InverterFed Three-Phase A.C. Drive in the Whole Speed Range Experimental Results. 6th Europ. Conf. on Power Electronics, Sevilla 1995, Vol. 3, pp. 399-404

[28] Depenbrock, M.; Foerth, Ch.; Hoffmann, F.; Koch, S.; Steimel, A.; Weidauer, M.: Speed-sensorless stator-flux-oriented control of induction motor drives in traction. Communications - Scientific Letters of the University of Zilina 2-3/2001, pp. 68-75

[29] Amler, G.; Sperr, F.; Hoffmann, F.: Highly dynamic and speed sensorless control of traction drives. 10th Europ. Conf. on Power Electronics (EPE), Toulouse 2003

[30] Weidauer, M.; Foerth, C.; Robust speed-sensorless control of induction motors in traction applications (in German). Intern. ETGCongress, Karlsruhe 2007; ETG-Fachbericht 107, pp. 431-440

[31] Thoma, M.; Jampen, U.: Statische Frequenzumrichteranlage Wimmis (Schweiz). Elektrische Bahnen 104 (2006), H. 12, S. 576-583

[32] Dicks, H.; Janning, J.: Standardumrichter Typ BAUM für DB Energie. Elektrische Bahnen 98 (2000), H. 10, S. 364-373

[33] Wrede, H.; Umbricht, U.: Development of a 413 MW railway power supply converter. 35th Ann. Conf. of IEEE Industrial Electronics Society (IECON '09), Porto 09

[34] Lesnicar, A.; Marquardt, R.: A new modular voltage source inverter topology. 10th European Power Electronic Conf. (EPE), Toulouse 2003

[35] Menth, St.; Meyer, M.: Low-frequency power oscillations in electric railway systems. Elektrische Bahnen 104 (2006), H. 5, S. 216221

[36] Heising, C., Oettmeier, M., Danielsen, St., Staudt, V. and Steimel, A.: Improvement of low-frequency railway power system stability using an advanced multivariable control concept. 35th Ann. Conf. of the IEEE Industrial Electronics Society (IECON'09), Porto 2009, pp. $565-570$ 